\title{
Collective Labor Supply: A Single-Equation Model and Some Evidence from French Data*
}

\author{
Olivier Donni ${ }^{\dagger}$ \\ THEMA, University of Cergy-Pontoise \\ Nicolas Moreau ${ }^{\ddagger}$ \\ GREMAQ and LIRHE, University of Toulouse 1
}

June 8, 2005

*This paper was partly written while Nicolas Moreau was visiting CIRPEE, Université Laval, whose hospitality and financial support are gratefully ackowledged. We thank François Bourguignon for useful comments and suggestions. We bear the sole responsibility for any remaining errors.

†THEMA, Université de Cergy-Pontoise, 33 Boulevard du Port, 95011 Cergy Cedex, France. Email: olivier.donni@eco.u-cergy.fr.

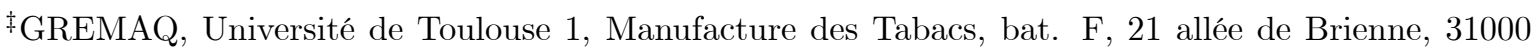
Toulouse, France. Email: nicolas.moreau@univ-tlse1.fr. 


\begin{abstract}
In Chiappori's (1988) collective model of labor supply hours of work are supposed flexible. In many countries, however, male labor supply does not vary much. In that case, the husband's labor supply is no longer informative about the household decision process and individual preferences. To identify structural components of the model, additional information is needed. We thus consider an approach in which the wife's labor supply is expressed as a function of the household demand for one specific good. We demonstrate that the main properties of Chiappori's initial model are preserved and apply our results on French data.
\end{abstract}

Keywords : Collective Models, Labor Supply, Intra-household Distribution, Conditional Demand.

Classification JEL : D11, D12, D13, J22. 


\section{Introduction}

The collective model of labor supply, developed by Chiappori $(1988,1992)$, is by now a standard tool for analyzing household decisions. This model is based on two fundamental hypotheses - each household member is characterized by specific preferences, and decisions result in Pareto-efficient outcomes - which turn out to be sufficient to generate strong testable restrictions on spouses' labor supply. Moreover, if consumption is purely private and agents are egoistic, the characteristics of the structural model, such as individual preferences and the rule that determines the distribution of welfare within the household, can be identified from the observation of spouses' labor supply. ${ }^{1}$

These features of the collective model have turned out to be very attractive, and the number of empirical studies based on Chiappori's initial framework is considerable. These include Bloemen (2004, Netherlands), Chiappori, Fortin and Lacroix (2002, United States), Clark, Couprie and Sofer (2004, United Kingdom), Fortin and Lacroix (1997, Canada), Moreau and Donni (2002, France) and Vermeulen (2005, Belgium). However, the large majority of these investigations does not account for the fact that, in most developed countries, male labor supply is rigid and largely determined by exogenous constraints. If the dispersion in husbands' hours is very limited and/or does not stem from spouses' optimal decisions, the identification results given in Chiappori's papers may well be inappropriate.

One important exception in the empirical studies devoted to collective models is given

\footnotetext{
${ }^{1}$ The collective model of labor supply has recently been extended in various directions. Chiappori, Blundell and Meghir (2004) allow for the existence of both private and public consumption. Donni (2003) incorporates the possibility of non-participatory decisions and non-linear taxation. Apps and Rees (1997), Chiappori (1997) and Donni (2005a) recognize the role of domestic production and allow for the fact that a proportion of non-market time is spent producing goods and services within the household. Fong and Zhang (2001) study a collective model of labor supply where there are two distinct types of leisure: one type is each person's independent (or private) leisure, and the other type is spousal (or public) leisure. See Vermeulen (2002) and Donni (2005b) for a survey of collective models.
} 
by Blundell et alii (2004). These authors emphasize that in the United Kingdom (but this certainly holds true in other countries), if men work, they work nearly always full-time; the wife's working hours, on the contrary, are largely dispersed. The theoretical model they develop then allows for these essential features: the wife's labor supply is assumed to be continuous, whereas the husband's choices are assumed to be discrete (either fulltime working or non-working). These authors show that the main conclusions which were derived by Chiappori in the initial context are still valid here. One drawback, however, is that the result of identifiability and testability given by Blundell et alii (2004) holds only if the husband's choice between full-time working and non-working is free; in particular, it could be seriously misleading if unemployment is mistakenly interpreted as the decision of not participating in the labor market.

In the present paper we deal with the rigidity of the husband's behavior in the French labor market. The approach is quite different from Blundell et alii's (2004), though. The starting observation is that the variability in the husband's working hours is very limited. In addition, since the behavior of the few husbands who do not work can probably be explained by exogenous constraints (e.g., involuntary unemployment), the employment status of the husband can hardly give reliable information about individual preferences and the decision process. The strategy adopted in what follows is then to exploit the information in household consumption to derive testable restrictions and identify the intrahousehold distribution of welfare. ${ }^{2}$ More precisely, we propose a very simple approach to model wives' labor supply, in which the wife's behavior is explained by her wage rate, other household incomes, socio-demographic variables and the demand for one good consumed at the household level. In that case, as is explained in what follows, the level of the conditioning good summarizes the most important characteristics of the decision process. We then demonstrate that the estimation of this single-equation permits to carry out tests of collective rationality and identify some elements of the structural model. In

\footnotetext{
${ }^{2}$ The strategy is thus analogous in some respects to that in Donni (2005c), who estimates a system of household demands together with one labor supply.
} 
addition we also show that the present framework is compatible with home production if the production function belongs to some specific family of separable technologies.

This framework is advantageous at three levels. Firstly, the theoretical results do not postulate a particular explanation for the rigidity of the husband's behavior. Contrary to Blundell et alii (2004), identification does not exploit the quite limited variations in husbands' working hours, which may well stem from demand side constraints. Secondly, the econometric techniques developed for the estimation of single-equation models can be used to estimate the wife's labor supply, since the determination of the demand for the conditioning good needs not to be explicitly modelled. Thirdly, the variables which affect the distribution of power within the household need not to be exactly observed. They are summarized by the level of the conditioning good. This point is explained in the remainder of the paper.

These theoretical results are followed by an empirical application using French data for those couples in which the wife participates in the labor market and the husband works full-time. The conditioning good is the household expenditures on food at home. The wife's labor supply is then estimated by GMM, taking into account the selection bias (which results from the selection of the sample). The restrictions which are derived from Pareto efficiency are tested and not rejected by the data.

The paper is structured as follows. The theoretical model is developed in Section 2 and a very general functional form is presented in Section 3. The data and the empirical results are described in Section 4. All the proofs are collected in Appendix A.

\section{Theory}

\subsection{Basic framework}

Preferences and budget set. We consider only the case of a two-person household, consisting of a wife $(f)$ and a husband $(m)$, who make decisions about leisure and con- 
sumption. ${ }^{3}$ The market labor supply of spouse $i(i=m, f)$ is denoted by $h_{i}$, with market wage rate $w_{i}$. The private consumption can be broken down into two aggregate goods, which are denoted by $c_{i}$ and $x_{i}$, so that each household member is characterized by specific preferences over $\left(h_{i}, c_{i}, x_{i}\right)$. These can be represented by utility functions of the form:

$$
u_{i}\left(T-h_{i}, c_{i}, x_{i} ; z\right)
$$

where $T$ is total time endowment and $z$ is a vector of socio-demographic factors, ${ }^{4}$ that are both strongly concave, infinitely differentiable and strictly increasing in $\left(T-h_{i}\right), c_{i}$ and $x_{i}$. The household members are said to be 'egoistic' in the sense that their utility only depends on their own consumption and leisure. This may seem restrictive but, as shown in Chiappori (1992), all the results immediately extend to the case of 'altruistic' agents in a Beckerian sense with utilities represented by the form:

$$
W_{i}\left[u_{m}\left(T-h_{m}, c_{m}, x_{m} ; z\right), u_{f}\left(T-h_{f}, c_{f}, x_{f} ; z\right)\right]
$$

where $W_{i}(\cdot)$ is a strictly increasing function. The crucial hypothesis is the existence of some type of separability in the spouses' preferences.

At this stage, we suppose that there is no domestic production. ${ }^{5}$ Let $y$ be the household non-labor income. The budget set is then written as:

$$
y+h_{m} w_{m}+h_{f} w_{f} \geqslant c+x
$$

and

$$
0 \leqslant h_{i} \leqslant T, \quad c_{i} \geqslant 0, \quad x_{i} \geqslant 0
$$

where $c=c_{m}+c_{f}$ and $x=x_{m}+x_{f}$. We may note that, in consumer expenditure surveys, consumption is usually recorded at the household level. We thus assume in what follows that the econometrician observes $h_{i}, c$ and $x$, but does not observe $c_{i}$ and $x_{i}$.

\footnotetext{
${ }^{3}$ The couple is not necessarily married. The terminology is chosen for convenience.

${ }^{4}$ For convenience we suppose that the same socio-demographic factors $z$ enter both utility functions.

${ }^{5}$ This assumption is relaxed in Section 2.5. We shall show that our theoretical results continue to hold with domestic production for a general class of production technologies.
} 
In France - and in many other countries for that matter - the distribution of the number of men's working hours is very concentrated around the full-time bound. Consequently, as a convenient approximation at least, we assume the husband's labor supply is constant, i.e.,

$$
h_{m}=h^{*},
$$

where $0<h^{*} \leqslant T$. The reason for this rigidity is beyond the scope of this paper. It may result from the husband's preferences, demand-side constraints or institutional rigidities. Quite importantly, however, our theoretical results are general in the sense that they do not rely on a specific explanation of the husband's behavior.

Pareto efficiency and optimization. The main originality of the efficiency approach is the fact that the household decisions result in Pareto-efficient outcomes and that no additional assumption is made about the process. That means, for any wage-income bundle, the labor-consumption bundle chosen by the household is such that no other bundle in the budget set could leave both members better off. This assumption, even if not formally justified, has a good deal of intuitive appeal. First of all, the household is one of the preeminent examples of a repeated game. Then, given the symmetry of information, it is plausible that agents find mechanisms to support efficient outcomes since cooperation often emerges as a long-term equilibrium of repeated noncooperative relations. A second point is that axiomatic models of bargaining with symmetric information, such as Nash or Kalai-Smorodinsky bargaining, which have been previously used to analyze negotiation within the household (Manser and Brown, 1980, and McElroy and Horney, 1981), assume efficient outcomes.

Taking account of the restriction on the husband's working hours, Pareto-efficiency essentially means that a scalar $\mu$ exists so that the household behavior is a solution to the following program:

$$
\max _{\left\{h_{i}, c_{i}, x_{i} \mid i=m, f\right\}}(1-\mu) \cdot u_{f}\left(T-h_{f}, c_{f}, x_{f} ; z\right)+\mu \cdot u_{m}\left(T-h_{m}, c_{m}, x_{m} ; z\right)
$$


with respect to (2)-(4). The parameter $\mu$ has an obvious interpretation as a 'distribution of power' index. If $\mu=0$, the household behaves as though the wife always got her way, whereas, if $\mu=1$, it behaves as if the husband was the effective dictator. To obtain well-behaved labor supplies and demands, however, we assume that $\mu$ is a single-valued and infinitely differentiable function of $w_{f}, w_{m}, y$ and $z$, with a range comprised between 0 and 1 . This is standard in the literature on collective models.

\subsection{Decentralization and functional structure}

Let us define $\psi=y+h^{*} w_{m}$ as the 'nonwife' income. As is well-known (Chiappori, 1992), if agents are egoistic and consumption is purely private, Pareto efficiency implies that the household decision process can be decentralized. More precisely, if $\left(h_{m}, h_{f}, c_{m}, c_{f}, x_{m}, x_{f}\right)$ are solutions to Program (5), a sharing $(\rho, \psi-\rho)$ of nonwife income exists so that the husband's and the wife's behaviors can be described by the following programs:

A. Husband's Program:

$$
\begin{gathered}
\max _{c_{m}, x_{m}} u_{m}\left(T-h^{*}, c_{m}, x_{m} ; z\right) \text { subject to } c_{m}+x_{m} \leqslant \rho, \\
c_{m} \geqslant 0 \text { and } x_{m} \geqslant 0,
\end{gathered}
$$

B. Wife's Program:

$$
\begin{gathered}
\max _{h_{f}, c_{f}, x_{f}} u_{f}\left(T-h_{f}, c_{f}, x_{f} ; z\right) \text { subject to } c_{f}+x_{f}=\psi-\rho+h_{f} w_{f}, \\
0 \leqslant h_{f} \leqslant T, c_{f} \geqslant 0 \text { and } x_{f} \geqslant 0 .
\end{gathered}
$$

In general, the sharing of $\psi$ will depend on $w_{f}, w_{m}, y$ and $z$. Hence, without loss of generality, we write the husband's share as: $\rho=\rho\left(w_{f}, \psi, s, z\right)$, where $s=y / \psi$ is the ratio of nonlabor income and nonwife income. In standard terminology the variable $s$ is called a distribution factor. In what follows, the husband's share $\rho$, expressed as a function of $\left(w_{f}, \psi, s, z\right)$, is referred to as the sharing rule. 
The result above determines the functional structure that characterizes the wife's labor supply and the household's demand for goods. Let us denote the solutions to the wife's and husband's optimization programs (in terms of what is observable) by $\bar{c}\left(w_{f}, \psi, s, z\right)$, $\bar{x}\left(w_{f}, \psi, s, z\right)$ and $\bar{h}_{f}\left(w_{f}, \psi, s, z\right)$. Then we have:

$$
\bar{x}\left(w_{f}, \psi, s, z\right)=\zeta_{m}\left(\rho\left(w_{f}, \psi, s, z\right), z\right)+\zeta_{f}\left(w_{f}, \psi-\rho\left(w_{f}, \psi, s, z\right), z\right),
$$

where $\zeta_{m}$ and $\zeta_{f}$ are the husband's and wife's Marshallian demand for good $x$ respectively, and

$$
\bar{h}_{f}\left(w_{f}, \psi, s, z\right)=\eta_{f}\left(w_{f}, \psi-\rho\left(w_{f}, \psi, s, z\right), z\right)
$$

where $\eta_{f}$ is the wife's Marshallian labor supply. In particular, this relation satisfies Slutsky Positivity :

$$
\frac{\partial \eta_{f}}{\partial w_{f}}-\frac{\partial \eta_{f}}{\partial(\psi-\rho)} \cdot h_{f}>0
$$

for an interior solution. Note that the husband's wage rate influences the husband's behavior only through the individual shares of nonwife income. In particular the function $\zeta_{m}$ is independent of $w_{m}$ (conditionally on $\rho$ ). This property is a direct consequence of the husband's labor supply rigidity.

\subsection{The s-conditional approach}

In the present section we define a specific concept of conditional labor supply whereby the labor supply is expressed as a function of various variables and the level of good $x$. Note that conditional demands or supplies are often used in traditional analysis where a single utility function is assumed. ${ }^{6}$ However, the conditional function concerned here is somewhat different.

First, let us assume that:

$$
\frac{\partial \bar{x}}{\partial s} \neq 0
$$

\footnotetext{
${ }^{6}$ See for instance Pollak (1969), Chavas (1984), Browning and Meghir (1991) or Browning (1998). These authors define different concepts of conditional demands in the traditional framework.
} 
in an open subset of the domain of $\bar{x}\left(w_{f}, \psi, s, z\right)$, i.e., the source of nonwife income (locally) influences the demand for good $x$. Then, from the implicit function theorem, the demand for good $x$ can be inverted on $s$ to yield $s=\bar{s}\left(w_{f}, \psi, x, z\right)$. Let us incorporate this into the wife's share of income and obtain what we call the 's-conditional' sharing rule, denoted by

$$
\kappa\left(w_{f}, \psi, x, z\right)=\rho\left(w_{f}, \psi, \bar{s}\left(w_{f}, \psi, x, z\right), z\right)
$$

The s-conditional sharing rule has a specific property that is described in the following lemma.

Lemma 1 The s-conditional sharing rule is implicitly defined as the solution of: $x=$ $\zeta_{m}\left(\kappa\left(w_{f}, \psi, x, z\right), z\right)+\zeta_{f}\left(w_{f}, \psi-\kappa\left(w_{f}, \psi, x, z\right), z\right)$.

The proof is straightforward: for any $\kappa$, the equation of demand for good $x$ must be identically satisfied. This implies that the s-conditional sharing rule has a property of separability.

Now let us assume that there are no corner solutions. In particular the wife participates in the labor market. We then introduce the s-conditional sharing rule into the wife's labor supply and obtain:

$$
h_{f}\left(w_{f}, \psi, x, z\right)=\eta_{f}\left(w_{f}, \psi-\kappa\left(w_{f}, \psi, x, z\right), z\right)
$$

where $\kappa\left(w_{f}, \psi, x, z\right)$ has the property given in Lemma 1 . We shall refer to this concept as the 's-conditional' labor supply. ${ }^{7}$ Note that in (10) the information concerning the source of nonwife income, represented by $s$, is completely summarized by the level of the conditioning good $x$.

There are two distinct advantages to modelling an s-conditional labor supply instead of a direct one. Indeed, in modelling an s-conditional labor supply, there is no need:

\footnotetext{
${ }^{7}$ This concept is not completely original, though. Bourguignon, Browning and Chiappori (1995) examine this form of conditional functions in the context of demand analysis with constant prices. Donni (2004) considers the case of variable prices. However, these authors suppose that the conditioning good is consumed by only one person in the household, which makes things much simpler.
} 
(i) to model the determination of the conditioning good explicitly.

The s-conditional approach does not require an explicit structural model for the conditioning good at all. In contrast to usual collective models of labor supply à la Chiappori $(1988,1992)$, the s-conditional labor supply can be estimated with single-equation techniques. ${ }^{8}$ This is useful because the estimation of labor supply models is generally very expensive in computer-time.

(ii) to observe the distribution of nonwife income between its sources.

This is particularly compelling since, in empirical work, such information is often unreliable. More generally, the effect of any distribution factor, even unobserved or unknown for the econometrician, is incorporated in the conditioning good.

Nevertheless, the attractiveness of the s-conditional approach largely depends on the properties of s-conditional labor supplies, namely, whether the underlying assumptions are testable and the structural model identifiable from the observation of one s-conditional labor supply. These important questions are examined in the next section.

\subsection{Properties of s-conditional labor supplies}

In order to investigate the testability and identifiability issues we assume that the wife's s-conditional labor supply exists over an open subset $\mathcal{S}$. We now introduce some pieces of notation:

$$
\begin{aligned}
& \alpha\left(w_{f}, \psi, x, z\right)=-\frac{\partial h_{f}}{\partial \psi}\left(\frac{\partial h_{f}}{\partial x}\right)^{-1} \\
& \beta\left(w_{f}, \psi, x, z\right)=\frac{\partial h_{f}}{\partial x}\left(\frac{\partial \alpha}{\partial \psi} \frac{\partial h_{f}}{\partial x}-\frac{\partial \alpha}{\partial x} \frac{\partial h_{f}}{\partial \psi}\right)^{-1}
\end{aligned}
$$

In the discussion of Proposition 2 below, we shall show that $\alpha\left(w_{f}, \psi, x, z\right)$ represents the slope of the husband's Marshallian demand for good $x$, whereas $\beta\left(w_{f}, \psi, x, z\right)$ corresponds to the inverse of the derivative of this slope.

\footnotetext{
${ }^{8}$ This is also an advantage over the approach used in Donni (2005c), which is very cumbersome.
} 
Let us assume now that the wife's s-conditional labor supply satisfies some regularity conditions.

Assumption R The wife's s-conditional labor supply is such that

$$
\frac{\partial h_{f}}{\partial x} \neq 0, \quad \frac{\partial \alpha}{\partial x} \neq 0 \quad \text { and } \quad \frac{\partial \alpha}{\partial \psi} \frac{\partial h_{f}}{\partial x} \neq \frac{\partial \alpha}{\partial x} \frac{\partial h_{f}}{\partial \psi},
$$

for any $\left(w_{f}, \psi, x, z\right) \in \mathcal{S}$.

Note that, if the wife does not participate in the labor market, these conditions do not hold, and the conclusions that follow are not valid.

The next result states that the s-conditional sharing rule can be retrieved from the sole observation of the wife's s-conditional labor supply.

Proposition 2 Let us assume that the wife's s-conditional labor supply $h_{f}\left(w_{f}, \psi, x, z\right)$ satisfies $\mathrm{R}$. Then,

(a) the s-conditional sharing rule can be retrieved on $\mathcal{S}$ up to a function $k(z)$ of $z$; specifically, its derivatives are given by

$$
\frac{\partial \kappa}{\partial w_{f}}=\frac{\partial \alpha}{\partial w_{f}} \beta, \quad \frac{\partial \kappa}{\partial x}=\frac{\partial \alpha}{\partial x} \beta, \quad \frac{\partial \kappa}{\partial \psi}=\frac{\partial \alpha}{\partial \psi} \beta
$$

(b) for each choice of $k(z)$, the wife's marginal rate of substitution between total consumption $(c+x)$ and leisure $(T-h)$, i.e., the preferences between total consumption and leisure, is uniquely defined;

(c) the wife's Marshallian labor supply and the individual Marshallian demands can be retrieved up to a function of $z$.

The complete proof of this proposition is given in Appendix A. We briefly give the first step of the argument here. By definition, the slope of the husband's Marshallian demand for good $x$ is given by the increase in $x$ due to a one-unity variation in $\kappa$, keeping $\psi-\kappa, w_{f}$ and $z$ constant. Note now that $h_{f}$ depends only on $\psi-\kappa, w_{f}$ and $z$. Then, a 
one-unity variation in $\psi$, so that $h_{f}, w_{f}$ and $z$ remain unaffected, provides the slope of the husband's Marshallian demand. Consequently, if we apply the implicit function theorem to $h_{f}\left(w_{f}, x, \psi, z\right)$ such that $x$ is differentiated with respect to $\psi$, we obtain the slope of the husband's Marshallian demand:

$$
\frac{\partial \zeta_{m}}{\partial \kappa}=-\frac{\partial h_{f} / \partial \psi}{\partial h_{f} / \partial x}=\alpha
$$

Note that $\partial \zeta_{m} / \partial \kappa$ (and thus $\alpha$ ) depends only on $\kappa$ and $z$. The identification of the sconditional sharing rule then follows from the differentiation of (11) and the resolution of the system of partial differential equations that results.

The s-conditional approach has two main drawbacks as far as identification issues are concerned. Firstly, even if the s-conditional sharing rule can be recovered (up to a function of $z$ ), its theoretical interpretation is unclear. The reason is that the s-conditional sharing rule is expressed as a function of the level of good $x$, which is endogenously determined. Secondly, the s-conditional sharing rule and the other structural elements can be retrieved as long as the wife participates in the labor market but the identification cannot be extended beyond the participation set. However, these drawbacks are simply a converse of the fact that we need less information to estimate an s-conditional labor supply than a system of unconditional labor supply and demand of goods, as in Donni (2005c). In particular there is neither a need to observe the level of the demand for good $x$ when the wife does not work, nor one to observe the sources of nonwife income.

We show in the next proposition that the wife's s-conditional labor supply has to satisfy some constraints to be consistent with collective rationality.

Proposition 3 Let us assume that the wife's s-conditional labor supply $h_{f}\left(w_{f}, \psi, x, z\right)$ satisfies $\mathrm{R}$. Then, for any $\left(w_{f}, \psi, x, z\right) \in \mathcal{S}$,
(a) $\frac{\partial h_{f}}{\partial w_{f}}-\frac{\partial h_{f}}{\partial x}\left(\frac{\partial \alpha / \partial w_{f}}{\partial \alpha / \partial x}-\frac{h_{f}}{\beta(\partial \alpha / \partial x)}\right)>0$;
(b) $\frac{\partial \alpha}{\partial w_{f}} \frac{\partial \beta}{\partial x}-\frac{\partial \alpha}{\partial x} \frac{\partial \beta}{\partial w_{f}}=\frac{\partial \alpha}{\partial \psi} \frac{\partial \beta}{\partial x}-\frac{\partial \alpha}{\partial x} \frac{\partial \beta}{\partial \psi}=0$. 
These restrictions provide a joint test of collective rationality under specific assumptions, i.e., consumption is purely private, there is no domestic production and agents are egoistic (or caring). The inequality (a) results from condition (8) transposed into the s-conditional context. The system of partial differential equations (b) is due to the separability property that characterizes (6) and (7). The proof of that is provided in Appendix A.

We now suppose that leisure and goods are superior (i.e., normal). In many circumstances this assumption is uncontroversial because goods are very aggregated. If so, the s-conditional approach implies several additional restrictions which are presented in the next proposition.

Proposition 4 Let us assume that the wife's s-conditional labor supply $h_{f}\left(w_{f}, \psi, x, z\right)$ satisfies $\mathrm{R}$. Then, for any $\left(w_{f}, \psi, x, z\right) \in \mathcal{S}$,

(a) if leisure is superior,

$$
\frac{\partial h_{f} / \partial x}{\beta(\partial \alpha / \partial x)}>0
$$

(b) if goods $x$ and c are superior (for both spouses),

$$
\min \left(1,1+\frac{1+w_{f}\left(\partial h_{f} / \partial x\right)}{\beta(\partial \alpha / \partial x)}\right)>\alpha>\max \left(0, \frac{1}{\beta(\partial \alpha / \partial x)}\right) .
$$

This result, which is a straightforward consequence of Proposition 2, provides a new test of collective rationality under the additional assumption of consumption superiority. In particular the second statement of Proposition 4 deserves some comments. If one inequality in this statement is violated by $\alpha$, then (at least) one slope of the four Engel curves must be negative. To illustrate that, let us remember that $\alpha$ coincides with the slope of the husband's Engel curve for good $x$. Then, if $\alpha<0$, good $x$ is inferior for the husband (but good $c$ is necessarily superior from the Engel's aggregation condition). On the contrary, if $\alpha>1$, good $x$ is superior and good $c$ is inferior. The interpretation of the other inequalities, which are related to the wife's behavior, are more complicated, though. The reader is referred to the proof in Appendix A. 


\subsection{Another interpretation: the role of domestic production}

Undoubtedly, the absence of domestic production is a serious shortcoming of the model developed above. Hence, in this subsection, we incorporate the fact that a proportion of time not allocated to market labor supply may be spent producing goods within the household. To do so, we suppose that $h_{i}^{1}=h_{i}+h_{i}^{2}$, where $h_{i}^{1}$ and $h_{i}^{2}$ respectively is spouse $i$ 's total labor supply and domestic labor supply. ${ }^{9}$ That means, non-market time can be broken down into time consumed in leisure, $T-h_{i}^{1}$, and time spent in domestic production, $h_{i}^{2}$. Then we suppose that goods can be produced using 'individual' technologies of the form:

$$
h_{i}^{2}=f_{i}\left(c_{i}^{2}, x_{i}^{2}\right)
$$

where $f_{i}$ is a function, increasing and strictly convex in its arguments, and $c_{i}^{2}$ et $x_{i}^{2}$ denote the proportion of goods $c$ and $x$ entering spouse $i$ 's production process, where as usual a positive number indicates an output and a negative number indicates an input. Note that goods $c$ and $x$ are marketable in the sense that they can either be purchased (or sold) in the market or produced at home. ${ }^{10}$ Also, the prices are exogenously fixed by the market.

In the specification of the production technology, the fact that $f_{i}$ does not depend on $h_{j}^{2}(j \neq i)$ is crucial in the development that follows. That implies there is neither substitutability nor complementarity in spouses' time inputs. Overall, this assumption seems to be supported (as a valid approximation at least) by the rare empirical studies of domestic activities (e.g., Graham and Greene, 1984). Now let us suppose that spouses' utility is a function of leisure (instead of nonmarket time) and consumption. We have:

$$
v_{i}\left(T-h_{i}^{1}, c_{i}^{1}, x_{i}^{1}\right)
$$

\footnotetext{
${ }^{9}$ To simplify the presentation of this subsection and emphasize the intuition, we do not take into account the rigidity of the husband's labor supply and we do not specify the various non-negativity restrictions on domestic labor supplies and consumptions.

${ }^{10}$ For example, meals can be produced within the household or bought from a caterer. Gronau (1977) gives a justification of this traditional assumption.
} 
where $c_{i}^{1}$ and $x_{i}^{1}$ denote the proportion of $c$ and $x$ which is 'directly' consumed by spouse $i$ (which includes the outputs of the production process and excludes the inputs). We have: $c_{i}^{1}=c_{i}+c_{i}^{2}$ and $x_{i}^{1}=x_{i}+x_{i}^{2}$, where $c_{i}$ and $x_{i}$ denote the quantity of goods purchased in the market for spouse $i$ 's use.

The basic idea of the reasoning is that if the production technology is of the form (12), the utility function (1) which is used in the preceding subsections can be derived from a more fundamental representation of preferences, described by (13). We have:

$$
u_{i}\left(h_{i}, c_{i}, x_{i}\right)=\max _{c_{i}^{1}, x_{i}^{1}, c_{i}^{2}, x_{i}^{2}} v_{i}\left(T-h_{i}-f_{i}\left(c_{i}^{2}, x_{i}^{2}\right), c_{i}^{1}, x_{i}^{1}\right)
$$

subject to

$$
c_{i}^{1}-c_{i}^{2}=c_{i}, \quad x_{i}^{1}-x_{i}^{2}=x_{i}
$$

Since the price of goods is constant (and equal to one), this result is a straightforward application of the Hicks' aggregation theorem. The intuition goes as follows. The allocation process can now be represented in three stages. Firstly, spouses agree on a sharing of nonwife income as previously. Secondly, each spouse maximizes $u_{i}$ with respect to $h_{i}, c_{i}$ and $x_{i}$, taking account of the wife's share of nonwife income. Thirdly, each spouse maximizes $v_{i}$ with respect to $c_{i}^{1}, x_{i}^{1}, c_{i}^{2}$ and $x_{i}^{2}$, taking account of their individual production technology and their preceding choices of $h_{i}, c_{i}$ and $x_{i}$. This last stage, which characterizes the domestic production interpretation, is described by Program (14) above. Note that the arbitrage between domestic and market activities is determined by the comparison of market wage rate and domestic productivity. If productivity is high, it is profitable to devote a large proportion of time to domestic activities. This may explain the specialization of one spouse in market or domestic activities.

Now, if the interpretation above is accepted, the individual demands that are retrievable from Proposition 2 can be seen as the difference of the demands of goods which are directly consumed $\left(x_{i}^{1}, c_{i}^{1}\right)$ and those which are produced (or used as inputs) at home $\left(x_{i}^{2}, c_{i}^{2}\right)$. In other words, it represents the quantity of goods purchased by spouse $i$ with her share of nonwife income in the second stage of the decision process described above. 
In any case, however, the utility function $u_{i}$, which is (partially) identified from observed behavior, continues to represent a valid indicator of spouse $i$ 's welfare. In addition, the testability results presented in Proposition 3 and 4 are still valid in the domestic production interpretation.

\section{Parametric Specification of the Model}

\subsection{Quadratic Conditional Labor Supply}

In order to estimate and test the collective model previously developed we must first specify a functional form for the wife's s-conditional labor supply. Let us consider a very general, quadratic functional form:

$$
\begin{aligned}
h_{f}= & a_{00}(z)+a_{01} w_{f}+a_{02} \psi+a_{03} x+a_{11} w_{f}^{2}+a_{22} \psi^{2}+a_{33} x^{2} \\
& +a_{12} w_{f} \psi+a_{13} w_{f} x+a_{23} \psi x
\end{aligned}
$$

where $a_{01}, \ldots, a_{23}$ are parameters and $a_{00}$ is a function of observed and unobserved heterogeneity. To make things simple, we suppose that $a_{00}$ has a linear form: $a_{00}=\alpha^{\prime} z$, where $\alpha$ is a vector of parameters and $z$ a vector of socio-demographic factors.

This specification has the main advantage of allowing very flexible responses of hours to wage rate. To justify this flexibility, Figure 1 reports four locally weighted regressions of female hours on the wage rate. The thick regression line relates to a sample of households with nonwife income below the first quartile. The dotted regression line relates to a sample of households with nonwife income above the first quartile and below the median. The dashed regression line relates to a sample of households with nonwife income above the median and below the third quartile and the large dashed regression line to a sample of households with nonwife income above the third quartile. A clear non-monotonic relationship between hours and wages appears. Moreover, for a given wage rate, the slope of this relationship depends on nonwife income. The different curves also show 
a substantial income effect. Hence a flexible specification is necessary to grasp these features. ${ }^{11}$

The collective model yields a set of parametric restrictions on (15) that can be empirically tested. Using the results given in Proposition 3, we can show that the coefficients of this functional form have to satisfy the following restrictions: ${ }^{12}$

$$
2 a_{33} a_{12}-a_{13} a_{23}=a_{23} a_{23}-4 a_{33} a_{22}=0 .
$$

Note that these restrictions do not entail unrealistic constraints on behavior. Moreover, the Slutsky condition implies that

$$
\left(a_{01}-\frac{a_{03} a_{13}}{2 a_{33}}\right)+2\left(a_{11}-\frac{a_{13}^{2}}{4 a_{33}}\right) w_{f}-\left(a_{02}-\frac{a_{03} a_{23}}{2 a_{33}}\right) h_{f}>0 .
$$

In principle, this restriction can be globally imposed but it reduces excessively the flexibility of the functional form. Hence we prefer checking (17) for each observation.

Now, if these restrictions are imposed, the wife's Marshallian labor supply and the sharing rule can be retrieved. And, from the results given in Proposition 4, the superiority of goods $x$ and $c$ can be tested.

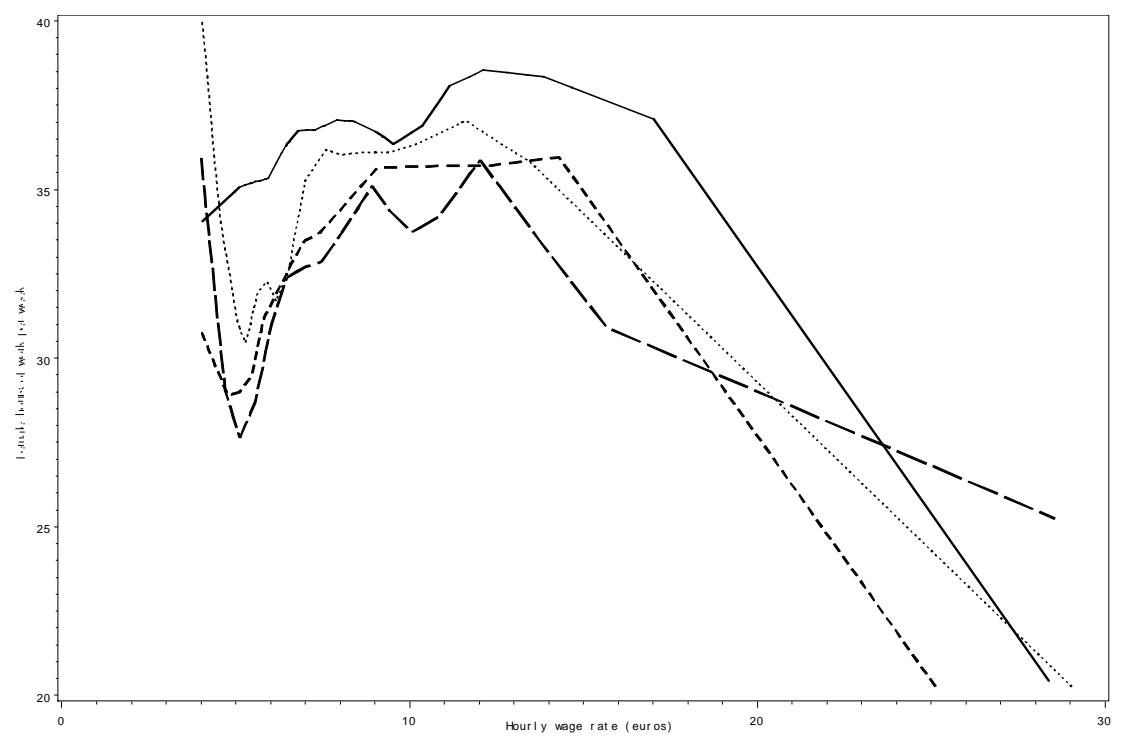

Figure 1: Locally weighted regression, FHBS 2000 data

\footnotetext{
${ }^{11}$ These results are only illustrative since no allowance is made for the endogeneity of the wage or nonwife income. Note that the data are sparse for $w_{f}$ greater than 20.

${ }^{12}$ These restrictions have been obtained using a mathematical computation software.
} 


\subsection{Recovering the Structural Parameters}

Sharing rule. Let us define $\Theta=a_{03}+a_{23} \psi+a_{13} w_{f}+2 a_{33} x$ and $\Delta=a_{03} a_{23}-2 a_{02} a_{33}$. The s-conditional sharing rule is quadratic and its derivatives are given by

$$
\frac{\partial \kappa}{\partial w_{f}}=a_{13} \frac{\Theta}{\Delta}, \quad \frac{\partial \kappa}{\partial \psi}=a_{23} \frac{\Theta}{\Delta} \quad \text { and } \quad \frac{\partial \kappa}{\partial x}=2 a_{33} \frac{\Theta}{\Delta} .
$$

Solving this system of three partial differential equations, we obtain the s-conditional sharing rule equation:

$$
\begin{aligned}
\rho= & K_{0}(z)+K_{1} w_{f}+K_{2} \psi+K_{3} x+K_{4} w_{f}^{2}+K_{5} \psi^{2}+K_{6} x^{2} \\
& +K_{7} w_{f} \psi+K_{8} w_{f} x+K_{9} \psi x
\end{aligned}
$$

where $K_{0}(z)$ is an unidentified function of $z$, and where

$$
\begin{array}{lll}
K_{1}=\frac{a_{03} a_{13}}{\Delta}, & K_{2}=\frac{a_{03} a_{23}}{\Delta}, & K_{3}=\frac{2 a_{03} a_{33}}{\Delta},
\end{array}
$$

It is also possible to recover the Marshallian labor supply associated with this setting.

Marshallian labor supply. The Marshallian labor supply does not depend on the conditioning good $x$ and takes the following form:

$$
h_{f}=A(z)+B w_{f}+C w_{f}^{2}+D(\psi-\rho),
$$

where

$$
\begin{array}{ll}
A(z)=a_{00}(z)+\left(a_{02}-\frac{a_{03} a_{23}}{2 a_{33}}\right) \times K_{0}(z), & B=a_{01}-\frac{a_{03} a_{13}}{2 a_{33}}, \\
C=a_{11}-\frac{a_{13}^{2}}{4 a_{33}}, & D=a_{02}-\frac{a_{03} a_{23}}{2 a_{33}} .
\end{array}
$$

Hence the wife's Marshallian labor supply belongs to the family of semi-quadratic specifications, and the normality of leisure implies that $D<0$. Note that the utility function that rationalizes this functional form exists in closed form and is given by Stern (1986). 
Slopes of the Engel curves. If goods $x$ and $c$ are superior, the slope of the Engel curves generates a strong test of collective rationality, as is explained in the discussion of Proposition 4. To carry out this test, these slopes have to be computed for the present functional form with the identification results given in Proposition 2. However, the formulae are quite complicated, so that the slopes are not exhibited here. Note that the positivity must be checked for each observation since the Engel curves are not linear.

\section{Data and Empirical Results}

\subsection{Data}

The data are taken from the French Household Budget Survey 2000 conducted by the French institute of economic and statistical information (INSEE). It contains detailed information on consumption, labor income, working hours, education and demographic characteristics. We select a sample of married and cohabiting couples where the adults are aged between 20 and 60 and available for the labor market. For this purpose, households where adults are disabled, retired or students are excluded. We also exclude households where adults are self-employed or farmers. The labor supply behavior of these two categories may indeed be rather different from salaried workers and, altogether, would require a different modeling strategy. We further select households where hours of work are positive for wives and at least 35 hours per week for husbands. We also restrict our sample to households with no pre-school (under 3) children in order to minimize the extent of nonseparable public goods within the household which is not accounted for in our model. Finally, since Browning and Chiappori (1998) argue that the hypothesis of efficiency in the intra-household decision process is more likely to be satisfied in stable couples, we further restrict our sample to households with at least two years of conjugal life. In all, these selection criteria lead us to 1670 observations.

The theory developed above requires the conditioning good $x$ to be private and non- 
Table 1: Descriptive Statistics of the Sample

\begin{tabular}{lccc}
\hline \hline & Mean & Median & Std. Dev. \\
\cline { 1 - 1 } The Whole Sample of Working Couples & & & \\
Male weekly hours of work & 40.65 & 39.00 & 8.09 \\
Female weekly hours of work & 33.24 & 35.00 & 9.56 \\
Our Selected Sample of 1670 Couples & & & \\
Female weekly hours of work & 33.33 & 35.00 & 9.64 \\
Female hourly wage rate & 8.78 & 7.71 & 4.18 \\
Annual food expenditures & 6101 & 5762 & 2810 \\
Annual nonwife income & 20632 & 16815 & 19479 \\
Wife's age & 41.00 & 41.00 & 8.15 \\
Number of children & 1.28 & 1.00 & 1.08 \\
\hline \hline
\end{tabular}

Notes: all monetary amounts in euros.

durable. In addition, since expenditures on nondurables are recorded in the survey on diaries covering two-week periods (and extrapolated for the year), infrequency of purchases may be a serious issue. We thus choose the household expenditure on food at home (including alcohol and tobacco) as the conditioning good. One advantage of using that variable is that the number of zeros is far lower than for other goods. However, we have also estimated the model with two other conditioning goods, namely, food away from home and clothing. In this case, the collective restrictions (16) and (17) are not rejected by the data but the coefficients are less precisely estimated than with food at home as the conditioning good. These estimations are summarized in Table 6 (Appendix B).

The female labor supply $h_{f}$ is the number of working hours per week. The wage rate $w_{f}$ is the average hourly earnings defined by dividing the wife's total labor income on all jobs over annual hours of work on all jobs. As the latter information is not included in the data, it is computed from $h_{f}$ and the number of months worked during the year.

The nonlabor income $y$ is defined as the nonlabor income net of savings and is given by the budget identity: $y=c+x-w_{m} h^{*}-w_{f} h_{f}$, so that the nonwife income $\psi$ is equal to: $\psi=c+x-w_{f} h_{f}$. That is, the nonwife income $\psi$ is the difference between annual 
household total consumption and female labor earnings. In doing that we follow Blundell and Walker (1986) and adjust nonwife income to be consistent with an intertemporally separable life-cycle model.

Finally, the socio-demographic factors $z$ include the number of children and the wife's age. ${ }^{13}$ As in Bourguignon and Magnac (1990), the wife's education level is used as an excluded instrument, instead of being used as a regressor.

Some descriptive statistics of the sample are exhibited in Table 1. The first and second rows of the table help us compare the distribution of male and female labor supply for working couples. On average, men work more than women and their labor supply is more concentrated. The comparison with the United-States, for instance, is striking. In the PSID of 1990, using a similar selection as done here for couples, we find that there is no obvious concentration in the distribution of hours, apart from the mode between 35 and 40 weekly hours. This spike itself concerns only 39.5\% (resp. 36.8\%) of US men (resp. women) in working couples compared to $65.5 \%$ (resp. $45.9 \%$ ) of the French men (resp. women) in working couples. We are inclined to believe that the variability in husbands' working hours can simply be disregarded by a study of French wives' behavior. This issue is examined below with a formal test of the rigidity of male labor supply.

\subsection{Endogeneity and Choice of Instruments}

The wage rate is computed as labor income divided by hours of work. This may induce the so-called 'division bias'. Moreover, the nonwife income and the food expenditures are likely to be endogenous as they are choice variables in the model. Therefore, we have chosen to instrument the wife's wage rate, the nonwife income, the food expenditures and their squares and cross-products. The possible endogeneity of children deserves further attention. On the one hand, we may assume that we only need to worry about the endogeneity of recently born children and can treat older children as predetermined. On

\footnotetext{
${ }^{13}$ In principle, the socio-demographic factors $z$ may also include variables related to the husband. However, these turn out to be insignificant.
} 
the other hand, there is some evidence that labor force behavior surrounding the first birth is a significant determinant of lifetime work experience (Browning, 1992). All things considered, this issue is an empirical one. Hence, since the exogeneity of the number of children is not rejected by our data, the estimations of the model we present below do not instrument the number of children. ${ }^{14}$

Now, an issue that requires some discussion relates to the choice of the instruments. We first assume that the husband's annual labor earnings are not correlated with the wife's taste for work. This is a reasonable assumption as, in our model, his labor supply is exogenously constrained. To grasp as much variation as possible in the endogenous regressors, we use a fourth order polynomial in the husband's labor earnings. We also use a second order polynomial in age and education for the wife and for the husband, and a second order polynomial in exceptional incomes (including inheritance, bequests and gifts) as instruments. This yealds sixteen instruments. ${ }^{15}$

Other instruments include a constant, the number of children, two dummies for husband's father's profession, a dummy variable for living in the Paris region, a cross-term of wife's education and husband's labor earnings. Since our estimation technique takes account of the selection of the sample, we also use the inverse Mill's ratio as an instrument. In all, we have twenty-three instruments. As usual, measurement error in the instruments is not supposed to be correlated with the response error for the endogenous variables. ${ }^{16}$

\footnotetext{
${ }^{14}$ However, our conclusions are still valid when the number of children is supposed to be endogenous. In that case the estimates differ only in that the coefficient of the number of children in (15) is no longer significant. These results are available upon request.

${ }^{15}$ These instruments are strongly correlated. To avoid this problem, we replace the polynomials with their corresponding principal components, that is orthogonal linear combinations of the original instruments. Estimations are then more stable.

${ }^{16}$ For Altonji (1986) and Altonji and Siow (1987) this assumption is reasonable, given that these variables are based on independent questions.
} 


\subsection{Results}

Before we present any further results we report the tests of the validity of the instruments.

\subsubsection{The validity of the instruments}

We first test the null hypothesis that none of the excluded instruments is correlated with the endogenous variables in the system of equations $Y=W \Gamma+e$, where $Y$ is the matrix of endogenous regressors, $W$ the matrix of instruments and $\Gamma$ a matrix of parameters and $e$ a matrix of random terms. The first panel of Table 7 in Appendix $\mathrm{C}$ shows $F$ statistic, corresponding $p$-value and adjusted $R$-square for each of the nine auxiliary regressions. The $p$-values are close to zero, indicating that the null hypothesis is clearly rejected. This gives evidence that the instruments are significant for all the endogenous variables. Note, however, that the $F$ statistic concerning the auxiliary regression on $\psi^{2}$ is relatively small (less than 5). In a 2SLS context Staiger and Stock (1997) suggest that estimates and confidence interval may be unreliable with first-stage $F$ 's this small. ${ }^{17}$ On the other hand, Bound, Jaeger and Baker (1995) mention that results should be interpreted with caution for first-stage $F$ statistics close to one.

To decide on the potential weakness of our instruments, we test whether the excluded instruments have enough explanatory power jointly for all the endogenous variables. For that purpose we use the test provided in Robin and Smith (2000). This test evaluates the rank of the coefficient matrix on the excluded instruments in the auxiliary regressions. A short account is in Blundell, Duncan and Meghir (1998). Let $\hat{\Lambda}$ be a consistent and asymptotically normal estimator of a $p \times k$ reduced form parameter matrix $\Lambda$ on the excluded instruments. ${ }^{18}$ Here we have four included instruments (a constant, the wife's age, the number of children and the inverse of Mill's ratio) so that there are $p=23-4=$

\footnotetext{
${ }^{17}$ We allow for heteroscedasticity of unknown form and estimate the model with GMM. We do not know whether these differences significantly affect their asymptotic or not.

${ }^{18}$ The matrix $\Lambda$ contains only the parameters of $\Gamma$ related to the excluded instruments in the sconditional labor supply equation.
} 
19 excluded instruments and $k=9$ endogenous variables. If $\Lambda$ is not full rank (i.e., $r k(\Lambda)<9$ ), the excluded instruments are weak for at least one endogenous variable. If $\Lambda$ is full rank (i.e., $r k(\Lambda)=9$ ), the excluded instruments have enough explanatory power jointly for all the endogenous variables. The Robin-Smith test of rank is based on the eigen values of $\hat{\Lambda}^{T} \hat{\Lambda}$.

Following the sequential procedure advocated in Robin and Smith (2000), we test for $H_{0}: r k(\Lambda)=r$ against $H_{1}: r k(\Lambda)>r$ for $r=1, \ldots, 9$ and halt at the first value of $r$ for which the test statistic indicates a nonrejection of $H_{0}$. The second panel of Table 7 in Appendix C exposes the results. Again, the $p$-values are close to zero. The null hypothesis $r k(\Lambda)=1$ is rejected, so is the null $r k(\Lambda)=2$, and so on until $r k(\Lambda)=8$ is also rejected: the reduced form coefficient matrix $\Lambda$ is full rank. We thus conclude that the excluded instruments are valid enough to give reliable estimates and confidence interval.

\subsubsection{Tests of husband's labor supply rigidity}

Our theoretical results crucially rely on the postulate that the wife's labor supply is independent of the husband's wage rate (conditionally on the levels of nonwife income and one reference good). This is a consequence of the husband's labor supply rigidity. In particular, if the husband's hours of work vary, the wife's labor supply will in general depend on the husband's wage rate. In that case our conclusions will be invalidated.

As a matter of fact, the data indicates that the dispersion of the husband's working hours is quite limited. In spite of that the husband's wage rate can possibly influence the wife's behavior and question the validity of our approach. Also, the rigidity of the husband's behavior must be tested. To do that, we introduce an additional term, $w_{m}$, in (15) and assess its significance. ${ }^{19}$ We perform this test whether $W_{m}$ is included or not in the set of instruments, where $W_{m}$ is the matrix of variables constructed from the

\footnotetext{
${ }^{19}$ In focusing on the role of the husband's wage rate in the s-conditional labor supply, this test is explicitly intended to test the implication of the dispersion in husband's working hours that may invalidate our theory.
} 
husband's labor income. In both cases the husband's wage rate has no impact statistically different from 0 .

We also test in the estimation of (15) for the endogeneity of the subset of instruments $W_{m}$. Suppose that the husband's wage rate is exogenous. Now it is orthogonal to the error term if husband's labor supply is exogenously constrained. Otherwise it is not. The corresponding test statistic is simply the difference in the criterion functions for GMM estimation with and without the questionable instruments $W_{m}$ (Ruud, 2000, p. 576). Under the null hypothesis of orthogonality it converges in distribution to a $\chi^{2}(k)$ random variable, where $k=5$ is the number of questionable instruments. The difference gives a test statistic of 8.139 (8.115 if the collective restrictions (16) are imposed). At conventional levels we do not reject the null hypothesis. ${ }^{20}$ In conclusion, even if the husband's working hours exhibit some dispersion, this should not prevent us from applying the present theory. In addition this test reinforces the evidence that the husband's labor supply is exogenously determined in France.

\subsubsection{Labor supply estimates}

Firstly, conditioning the sample on "stable" households with working wives and no children under 3 year of age may induce a selectivity bias. To account for all these selection rules we estimate a reduced-form participation equation and include the inverse Mill's ratio into the labor supply equation (15). The estimates of the selection equation are shown in Table 8 (Appendix C). This equation includes the wife's age and education, the husband's income and male and female unemployment rates as explanatory variables. The results show a strong effect of age, education and income, whereas the unemployment rates have a significant effect. Hence the labor supply equation, which excludes the latter variables, is well identified.

Let us now turn to the labor supply results. We denote the inverse Mill's ratio estimated from the participation equations by $\hat{\lambda}$ and the matrix of residuals obtained from

\footnotetext{
${ }^{20}$ Further details are available upon request.
} 
Table 2: Estimated Parameters of the Reduced Form Labor Supply

\begin{tabular}{|c|c|c|c|c|c|}
\hline & & \multicolumn{2}{|c|}{ Unrestricted Model } & \multicolumn{2}{|c|}{ Restricted Model } \\
\hline & & OLS & GMM & NLS & GMM \\
\hline \multirow[t]{2}{*}{$a_{01}$} & $w_{f}$ & $4.430^{* * *}$ & $4.727^{* * *}$ & $4.190^{* * *}$ & $4.501^{* * *}$ \\
\hline & & $(1.082)$ & $(1.109)$ & $(0.976)$ & $(0.989)$ \\
\hline \multirow[t]{2}{*}{$a_{02}$} & $\psi \times 10^{-2}$ & $-0.105^{*}$ & $-0.104^{*}$ & $-0.093^{* *}$ & $-0.095^{* *}$ \\
\hline & & $(0.059)$ & $(0.059)$ & $(0.042)$ & $(0.039)$ \\
\hline \multirow[t]{2}{*}{$a_{03}$} & $x$ & 0.003 & 0.003 & $0.004^{*}$ & $0.004^{* *}$ \\
\hline & & $(0.003)$ & $(0.003)$ & $(0.002)$ & $(0.002)$ \\
\hline \multirow[t]{2}{*}{$a_{11}$} & $w_{f}^{2}$ & $-0.106^{*}$ & $-0.118^{* *}$ & $-0.122^{* * *}$ & $-0.125^{* * *}$ \\
\hline & & $(0.056)$ & $(0.054)$ & $(0.044)$ & $(0.042)$ \\
\hline \multirow[t]{2}{*}{$a_{22}$} & $\psi^{2} \times 10^{-9}$ & 4.044 & 4.531 & 3.589 & $4.121^{*}$ \\
\hline & & $(3.031)$ & $(2.782)$ & $(2.446)$ & $(2.171)$ \\
\hline \multirow[t]{2}{*}{$a_{33}$} & $x^{2} \times 10^{-8}$ & 9.548 & 11.910 & 6.458 & 8.656 \\
\hline & & $(19.687)$ & $(19.780)$ & $(5.430)$ & $(5.579)$ \\
\hline \multirow[t]{2}{*}{$a_{12}:$} & $w_{f} \psi \times 10^{-2}$ & 0.005 & 0.006 & $0.006^{*}$ & $0.006^{* *}$ \\
\hline & & $(0.005)$ & $(0.005)$ & $(0.003)$ & $(0.003)$ \\
\hline \multirow[t]{2}{*}{$a_{13}$} & $w_{f} x \times 10^{-2}$ & -0.032 & $-0.033^{*}$ & -0.026 & $-0.029^{*}$ \\
\hline & & $(0.020)$ & $(0.019)$ & $(0.018)$ & $(0.017)$ \\
\hline \multirow[t]{2}{*}{$a_{23}:$} & $\psi x \times 10^{-9}$ & 1.374 & -18.600 & -30.450 & $-37.800^{* *}$ \\
\hline & & $(89.958)$ & $(92.490)$ & $(20.521)$ & $(18.600)$ \\
\hline \multirow[t]{2}{*}{$\alpha_{0}:$} & Intercept & $21.231^{* *}$ & $18.255^{*}$ & $17.932^{* *}$ & $16.137^{* *}$ \\
\hline & & $(9.444)$ & $(9.545)$ & $(6.946)$ & $(7.051)$ \\
\hline \multirow[t]{2}{*}{$\alpha_{\mathrm{ch}}:$} & Number of children & $-1.415^{* *}$ & $-1.393^{* *}$ & $-1.556^{* *}$ & $-1.462^{* *}$ \\
\hline & & $(0.718)$ & $(0.705)$ & $(0.642)$ & $(0.623)$ \\
\hline \multirow[t]{2}{*}{$\alpha_{\text {age }}:$} & Wife's age & $-0.257^{* * *}$ & $-0.275^{* * *}$ & $-0.261^{* * *}$ & $-0.274^{* * *}$ \\
\hline & & $(0.089)$ & $(0.085)$ & $(0.085)$ & $(0.079)$ \\
\hline \multirow[t]{2}{*}{$b_{\lambda}:$} & Inverse Mill's ratio & 1.880 & 2.472 & 2.428 & 2.848 \\
\hline & & $(2.276)$ & $(2.306)$ & $(2.039)$ & $(2.059)$ \\
\hline \multirow[t]{2}{*}{$b_{e_{w_{f}}}:$} & $\widehat{e}_{w_{f}}$ & $-3.433^{* * *}$ & & $-3.193^{* * *}$ & \\
\hline & & $(1.126)$ & & $(1.021)$ & \\
\hline \multicolumn{2}{|c|}{ Objective function } & & 9.393 & & 9.548 \\
\hline
\end{tabular}

Notes: Asymptotic standard errors in parentheses. Significance levels of 10, 5 and

$1 \%$ are noted $*, * *$ and $* * *$ respectively. 
the regression of the variables on the instruments (i.e., $Y=W \Gamma+e$ ) by $\widehat{e}$. The first and third columns of Table 2 provide estimates of the unrestricted and restricted models obtained by applying OLS (NLS) on the following relation:

$$
h_{f}=g\left(w_{f}, \psi, x, z ; a\right)+\hat{\lambda} b_{\lambda}+\hat{e} b_{e}+v
$$

where $g(\cdot)$ is the functional form (15) of the wife's labor supply, $v$ is a random term which represents the unobserved heterogeneity, and $a, b_{\lambda}$ and $b_{e}$ are parameters. The inclusion of the residuals in the labor supply equation is to control for the endogeneity of the regressors. It also provides a direct test of exogeneity. These are the $t$-statistics of the estimates of $b_{e}$; see Smith and Blundell (1986) or Blundell, Duncan and Meghir (1998) for a recent application. The asymptotic covariance matrix is computed using the results of Newey (1984) and Newey and McFadden (1994) to take into account that we are conditioning on generated regressors (i.e., $\hat{\lambda}$ and $\hat{e}) .{ }^{21}$ It is robust to heteroskedasticity of unknown form. To save space, only the test of exogeneity for the wife's wage rate is reported in Table 2. The wife's wage rate is likely to be measured with error and unobserved individual characteristics may be correlated with it. The residual of the regression of the wife's wage rate on the instruments is denoted by $\hat{e}_{w_{f}}$. Then, under the null hypothesis, the parameter $b_{e_{w_{f}}}$ corresponding to the residual $\hat{e}_{w_{f}}$ in equation (20) must be equal to zero. This is clearly rejected by the data. The wage rate has to be instrumented.

The second and fourth columns of Table 2 are the unconstrained and constrained models obtained by using GMM on the following equation:

$$
h_{f}=g\left(w_{f}, \psi, x, z ; a\right)+\hat{\lambda} b_{\lambda}+v
$$

The Hansen's test does not reject the validity of the instruments and the overidentifying restrictions. The test statistics 9.393 and 9.548 are less than the critical values of the $\chi_{0.05}^{2}(10)=18.307$ and of the $\chi_{0.05}^{2}(12)=21.026$. Note that, except for the interaction

\footnotetext{
${ }^{21}$ We account for the covariance of the coefficients $\hat{\Gamma}$ across the nine reduced forms. Still, we ignore the covariance between $\hat{\Gamma}$ and the estimated coefficients of the participation equation.
} 
term $\psi \times x$, the OLS and GMM estimations give similar results. However, under the presence of heteroskedasticity of unknown form, the GMM estimator attains greater efficiency (Davidson and MacKinnon, 1993, p. 599). Therefore, we only refer to the GMM results in what follows.

Let us take a closer look at the results of Table 2 . We note that the parameters of the unrestricted model are not estimated with precision. Only the wife's age, the number of children, the wage rate, its square, its interaction with food expenditures and the nonwife income have an impact at the $5 \%$ or $10 \%$ level. This lack of precision can be explained by the flexibility of our functional form. Nonetheless, the coefficients of the restricted model (i.e., with the imposition of conditions (16)) are very similar, but exhibit smaller standard errors, so that most of them are statistically significant at the $5 \%$ or $10 \%$ level. In particular the wife's age and the number of children have a significant, negative effect on the number of working hours. Moreover, the inverse Mill's ratio does not influence wife's labor supply. Apparently, the selection of the sample is not a serious issue.

We now turn to the test of the collective restrictions. To begin with, we perform a Newey-West's test of conditions (16). Since the difference in the function values (i.e., $9.548-9.393=0.155)$ is much smaller than the critical value, $\chi_{0.05}^{2}(2)=5.99$, we do not reject the restrictions at stake. However, this evidence in favor of the collective model must be interpreted with caution. Indeed, the standard error of the coefficient $a_{33}$ is large. Since this coefficient enters conditions (16), the test we carry out is not likely to be powerful. Also, the other tests at our disposal are essential to assess the validity of the model.

Using the estimates of the restricted model, we note that the Slutsky condition (17) is satisfied for a large majority $(93 \%)$ of the households in the sample, and the wife's leisure is superior. ${ }^{22}$ These results support the collective model and they will be more closely examined below. In addition, the positivity of the slopes of the Engel curves can

\footnotetext{
${ }^{22}$ Remember that the Marshallian labor supply is linear in income. Hence the superiority of leisure is 'global'. See Table 4 for more details.
} 
be checked since it is reasonable to assume that both goods are superior. This corresponds to a test of the second statement in Proposition 4. Actually we observe that the slopes of the four Engel curves are positive for $95.45 \%$ of the households in the sample. This confirms that the goods are superior and, incidentally, valid our estimations.

On the whole, the empirical tests we describe above do not reject the collective model concerned. Let us now consider various labor supply elasticities. These are shown in Table 3. The elasticities of the constrained and unconstrained models are similar and quite precisely estimated. Women's wage elasticities are positive and statistically significant. Income elasticities are negative and also statistically significant. The amplitude of these figures is somewhat different from that found with French data. For example, estimating a unitary model that accounts for non-linear taxation and nonparticipation, Blundell and Laisney (1988) report, at the sample mean, wage and income elasticities which are equal to 2 and -0.7 respectively. According to the specification used, these elasticities range from 0.05 to 1 respectively and from -0.3 to -0.2 in Bourguignon and Magnac (1990). The elasticities presented in Table 3 differ from previous estimations because our sample is restricted to working wives.

The estimation of the reduced form parameters allows us to retrieve some structural components of the model. The first panel of Table 4 reports the estimates of the parameters of the Marshallian labor supply (19). The coefficients have the expected signs but the effect of the wife's share of income is imprecisely estimated. Note also that the wife's Marshallian labor supply is backward bending. For small values of the wife's wage rate the substitution effect dominates the income effect so that an increase in the wife's wage rate has a positive impact on the working hours. For large values of the wife's wage rate the converse is true. Then the rejection of Slutsky positivity appears for some households in which the wife is characterized by a very large wage rate. The second panel of Table 4 includes the wage elasticity conditional on the sharing of nonwife income. This ignores any effect the wage rate may have on the intra-household decision process. We note that the wage elasticity is positive, concave and statistically significant at the $10 \%$ level. It is 
Table 3: Elasticities of labor supply

\begin{tabular}{lccc}
\hline \hline & Estimates & Asymptotic Std. Errors & $p$-Values \\
\hline \multicolumn{2}{l}{ Estimated wage elasticity of the unconstrained labor supply } & \\
\hline at $w_{f}=5.87$ (first quartile) & 0.374 & 0.103 & 0.000 \\
at $w_{f}=7.71$ (median) & 0.405 & 0.102 & 0.000 \\
at $w_{f}=10.33$ (third quartile) & 0.379 & 0.089 & 0.017 \\
Estimated wage elasticity of the constrained labor supply & \\
\hline at $w_{f}=5.87$ (first quartile) & 0.386 & 0.086 & 0.000 \\
at $w_{f}=7.71$ (median) & 0.416 & 0.088 & 0.000 \\
at $w_{f}=10.33$ (third quartile) & 0.384 & 0.083 & 0.000 \\
Estimated income elasticity of the unconstrained labor supply & 0.012 \\
\hline at $\psi=9842$ (first quartile) & -0.143 & 0.057 & 0.009 \\
at $\psi=16815$ (median) & -0.217 & 0.084 & 0.007 \\
at $\psi=27341$ (third quartile) & -0.286 & 0.106 & 0.006 \\
Estimated income elasticity of the constrained labor supply & 0.005 \\
at $\psi=9842$ (first quartile) & -0.136 & 0.049 & 0.005 \\
at $\psi=16815$ (median) & -0.207 & 0.074 & 0.098 \\
at $\psi=27341$ (third quartile) & -0.276 &
\end{tabular}

Notes: Asymptotic standard errors are computed with the Delta method. Elasticities are computed at $h_{f}=39$. Other covariates are at the sample mean.

Table 4: Estimated Parameters of the Structural Model: The Marshallian Labor Supply

\begin{tabular}{|c|c|c|c|}
\hline & Parameter & Asymptotic & $p$-Values \\
\hline & Estimates & Std Errors & \\
\hline$B: w_{f}$ & 11.011 & 6.187 & 0.075 \\
\hline$C: w_{f}^{2}$ & -0.374 & 0.235 & 0.111 \\
\hline$D: \quad(\psi-\rho) \times 10^{-2}$ & -0.011 & 0.013 & 0.368 \\
\hline \multicolumn{4}{|c|}{ Estimated wage elasticity of the Marshallian labor supply } \\
\hline at $h_{f}=39$, with $w_{f}=5.87$ (first quartile) & 0.996 & 0.529 & 0.060 \\
\hline at $h_{f}=39$, with $w_{f}=7.71$ (median) & 1.035 & 0.537 & 0.054 \\
\hline at $h_{f}=39$, with $w_{f}=10.33$ (third quartile) & 0.868 & 0.449 & 0.053 \\
\hline
\end{tabular}

Note: Asymptotic standard errors are computed with the Delta method. 
Table 5: Estimated Parameters of the Structural Model: The Sharing Rule

\begin{tabular}{llccc}
\hline \hline & & Parameter Estimates & Std. Error & p-Value \\
\hline$K_{1}:$ & $w_{f}$ & -56923.450 & 84039.060 & 0.498 \\
$K_{2}:$ & $\psi$ & -7.317 & 10.105 & 0.469 \\
$K_{3}:$ & $x$ & 33.532 & 41.789 & 0.422 \\
$K_{4}:$ & $w_{f}^{2}$ & 2180.998 & 2933.883 & 0.457 \\
$K_{5}:$ & $\psi^{2} \times 10^{-3}$ & 0.036 & 0.047 & 0.440 \\
$K_{6}:$ & $x^{2} \times 10^{-3}$ & 0.757 & 0.811 & 0.351 \\
$K_{7}:$ & $w_{f} \psi$ & 0.561 & 0.660 & 0.396 \\
$K_{8}:$ & $w_{f} x$ & -2.569 & 2.764 & 0.353 \\
$K_{9}:$ & $\psi x \times 10^{-2}$ & -0.033 & 0.038 & 0.382 \\
\hline
\end{tabular}

Estimated marginal impact of $w_{f}$ on the sharing rule ${ }^{a}$

\begin{tabular}{llll}
\hline at $w_{f}=5.87$ (first quartile) & -35436.950 & 53190.582 & 0.505 \\
at $w_{f}=7.71$ (median) & -27415.070 & 42778.054 & 0.522 \\
at $w_{f}=10.33$ (third quartile) & -15984.050 & 28432.382 & 0.574
\end{tabular}

Estimated marginal impact of $\psi$ on the sharing rule ${ }^{a}$

\begin{tabular}{|c|c|c|}
\hline at $\psi=9842$ (first quartile) & -3.699 & 5.690 \\
\hline at $\psi=16815$ (median) & -3.197 & 5.061 \\
\hline at $\psi=27341$ (third quartile) & -2.438 & 4.123 \\
\hline
\end{tabular}

Estimated marginal impact of $x$ on the sharing rule ${ }^{a}$

\begin{tabular}{llll}
\hline at $x=4136$ (first quartile) & 10.415 & 16.930 & 0.538 \\
at $x=5762$ (first quartile) & 12.876 & 19.291 & 0.504 \\
at $x=7694$ (first quartile) & 15.800 & 22.177 & 0.476 \\
\hline
\end{tabular}

Notes: Asymptotic standard errors are computed with the Delta method. ${ }^{a}$ : Other covariates are at the sample mean. 
twice as big as those reported in Table 3 and is close to one at the mean of the sample. It is noteworthy that this figure may be compared with what is found in the literature on collective models. For example, Chiappori, Fortin and Lacroix (2002) report a wage elasticity of 0.178 with United States data, Fortin and Lacroix (1997) a wage elasticity of 0.361 with Canadian data, and Moreau and Donni (2002) a wage elasticity of 0.394 with French data. The elasticities in Table 4 are substantially greater. However, they are compatible with previous researches since the standard errors of the estimated parameters are quite large. Finally, the sharing rule estimates are shown in the first panel of Table 5. The parameters turn out not to be precisely estimated. No coefficient is significant at the $10 \%$ level. In the second panel of Table 5 , the marginal impacts of the exogenous variables on the sharing rule are presented but the estimates are still imprecise.

\section{Conclusion}

In the present paper we suppose that the husband's labor supply is exogenously determined. We then advocate a simple approach to model the wife's labor supply, in which the wife's behavior is explained by her wage rate, other household incomes, socio-demographic variables and the demand for one good consumed at the household level. In this approach the level of the conditioning good can be interpreted as an indicator of the distribution of power within the household.

We then demonstrate that the estimation of a single equation (including one conditioning good as argument) permits to carry out tests of collective rationality and to identify some elements of the structural model. The simplicity of the estimation method suggests that the approach used in this paper is specially profitable to perform empirical tests.

Another important contribution of the present paper is to show that our approach (and the collective setting as a whole for that matter) is compatible with domestic production on the condition that the household production function belongs to some specific family of separable technologies. 
Finally, these theoretical considerations are followed by an empirical application using a French sample of working wives. We show that, overall, the collective restrictions are satisfied by the data. However, the estimates of the structural model are not precisely estimated. One way of dealing with that is to exploit the information on nonparticipating wives. Indeed, the parameters that enter the 'reduced' participation equation (used in constructing the inverse Mill's ratio) are not related to the parameters of the labor supply equation. In that case, the basic idea is to estimate a 'structural' participation equation, derived from the comparison of a shadow wage equation (incorporating the parameters of the wife's labor supply) and a market wage equation. The implementation of this idea raises some econometric difficulties, though. This is the topic of future work.

\section{Appendix A : Proof of Propositions}

\section{Proof of Proposition 2}

1. Identification of $\partial \zeta_{m} / \partial \kappa$. Differentiating the s-conditional labor supply with respect to $\psi$ and $x$ gives:

$$
\frac{\partial h_{f}}{\partial \psi}=\frac{\partial \eta_{f}}{\partial(\psi-\kappa)}\left(1-\frac{\partial \kappa}{\partial \psi}\right), \quad \frac{\partial h_{f}}{\partial x}=-\frac{\partial \eta_{f}}{\partial(\psi-\kappa)} \frac{\partial \kappa}{\partial x} .
$$

Since $\partial h_{f} / \partial \psi \neq 0$ from $\mathrm{R}$, this yields:

$$
-\frac{\partial h_{f}}{\partial \psi}\left(\frac{\partial h_{f}}{\partial x}\right)^{-1}=\left(1-\frac{\partial \kappa}{\partial \psi}\right)\left(\frac{\partial \kappa}{\partial x}\right)^{-1} .
$$

Similarly, using Lemma 1 and differentiating the household demand for good $x$ with respect to $\psi$ and $x$ gives:

$$
\begin{aligned}
1 & =\left(\frac{\partial \zeta_{m}}{\partial \kappa}-\frac{\partial \zeta_{f}}{\partial(\psi-\kappa)}\right) \frac{\partial \kappa}{\partial x} \\
\frac{\partial \zeta_{m}}{\partial \kappa} & =\left(\frac{\partial \zeta_{m}}{\partial \kappa}-\frac{\partial \zeta_{f}}{\partial(\psi-\kappa)}\right)\left(1-\frac{\partial \kappa}{\partial \psi}\right)
\end{aligned}
$$

or

$$
\frac{\partial \zeta_{m}}{\partial \kappa}=\left(1-\frac{\partial \kappa}{\partial \psi}\right)\left(\frac{\partial \kappa}{\partial x}\right)^{-1}
$$


Substituting (22) in (25) yields the husband's Engel curve:

$$
\frac{\partial \zeta_{m}}{\partial \kappa}=-\frac{\partial h_{f}}{\partial \psi}\left(\frac{\partial h_{f}}{\partial x}\right)^{-1}=\alpha .
$$

2. Identification of $\partial \kappa / \partial w_{f}, \partial \kappa / \partial \psi$ and $\partial \kappa / \partial x$. Differentiating (26) with respect to $w_{f}, \psi$ and $x$ yields:

$$
\frac{\partial^{2} \zeta_{m}}{\partial \kappa^{2}} \frac{\partial \kappa}{\partial w_{f}}=\frac{\partial \alpha}{\partial w_{f}}, \quad \frac{\partial^{2} \zeta_{m}}{\partial \kappa^{2}} \frac{\partial \kappa}{\partial \psi}=\frac{\partial \alpha}{\partial \psi}, \quad \frac{\partial^{2} \zeta_{m}}{\partial \kappa^{2}} \frac{\partial \kappa}{\partial x}=\frac{\partial \alpha}{\partial x} .
$$

Since

$$
\frac{\partial \alpha}{\partial \psi} \frac{\partial h_{f}}{\partial x} \neq \frac{\partial \alpha}{\partial x} \frac{\partial h_{f}}{\partial \psi}
$$

this system of partial differential equations, together with (22), can be solved with respect to $\partial \kappa / \partial w_{f}, \partial \kappa / \partial \psi$ and $\partial \kappa / \partial x$. That is,

$$
\frac{\partial \kappa}{\partial w_{f}}=\frac{\partial \alpha}{\partial w_{f}} \beta, \quad \frac{\partial \kappa}{\partial \psi}=\frac{\partial \alpha}{\partial \psi} \beta, \quad \frac{\partial \kappa}{\partial x}=\frac{\partial \alpha}{\partial x} \beta
$$

3. Identification of $\partial \eta_{f} / \partial(\psi-\kappa)$ and $\partial \eta_{f} / \partial w_{f}$. If we differentiate the wife's sconditional labor supply with respect to $x$ and $w_{f}$, we obtain:

$$
\frac{\partial h_{f}}{\partial x}=-\frac{\partial \eta_{f}}{\partial(\psi-\kappa)} \frac{\partial \kappa}{\partial x}, \quad \frac{\partial h_{f}}{\partial w_{f}}=\frac{\partial \eta_{f}}{\partial w_{f}}-\frac{\partial \eta_{f}}{\partial(\psi-\kappa)} \frac{\partial \kappa}{\partial w_{f}} .
$$

Since $\beta \neq 0$ and $\partial \alpha / \partial x \neq 0$, substituting (27) in (28) yields:

$$
\frac{\partial \eta_{f}}{\partial(\psi-\kappa)}=-\frac{\partial h_{f}}{\partial x} \frac{1}{\beta(\partial \alpha / \partial x)}, \quad \frac{\partial \eta_{f}}{\partial w_{f}}=\frac{\partial h_{f}}{\partial w_{f}}-\frac{\partial h_{f}}{\partial x} \frac{\partial \alpha / \partial w_{f}}{\partial \alpha / \partial x} .
$$

4. Identification of $\partial \zeta_{f} / \partial(\psi-\kappa)$ and $\partial \zeta_{f} / \partial w_{f}$. The slopes of the demand for good $x$ can be retrieved in a similar way. Substituting (26) and (27) in (23) gives:

$$
\frac{\partial \zeta_{f}}{\partial(\psi-\kappa)}=\alpha-\frac{1}{\beta(\partial \alpha / \partial x)}
$$

Differentiating the household demand for good $x$ with respect to $w_{f}$, and using (26) and (27) yield:

$$
\frac{\partial \zeta_{f}}{\partial w_{f}}=-\frac{\partial \alpha / \partial w_{f}}{\partial \alpha / \partial x}
$$


5. Identification of other elements. The derivatives of the Marshallian demands for good $c$ can be obtained from the individual budget constraints. Moreover, once the function $k(z)$ is picked up, the wife's total consumption can be retrieved. Then, the wife's utility function is derived as usual.

\section{Proof of Proposition 3}

1. Substituting (29) in (8) yields:

$$
\frac{\partial h_{f}}{\partial w_{f}}-\frac{\partial h_{f}}{\partial x}\left(\frac{\partial \alpha / \partial w_{f}}{\partial \alpha / \partial x}-\frac{h_{f}}{\beta(\partial \alpha / \partial x)}\right)>0
$$

2. From the Young's Theorem, the derivatives of the sharing rule have to satisfy a symmetry restriction. Simplifying yields:

$$
\frac{\partial \alpha}{\partial w_{f}} \frac{\partial \beta}{\partial x}-\frac{\partial \alpha}{\partial x} \frac{\partial \beta}{\partial w_{f}}=\frac{\partial \alpha}{\partial \psi} \frac{\partial \beta}{\partial x}-\frac{\partial \alpha}{\partial x} \frac{\partial \beta}{\partial \psi}=0
$$

\section{Proof of Proposition 4}

1. From (29),

$$
\frac{\partial h_{f} / \partial x}{\beta(\partial \alpha / \partial x)}>0
$$

if wife's leisure is normal. This gives the first statement in Proposition 4.

2. From (26) and (30),

$$
\alpha>0, \quad \alpha-\frac{1}{\beta(\partial \alpha / \partial x)}>0,
$$


if good $x$ is normal (for both spouses). From these expressions and the individual budget constraints, we obtain:

$$
\begin{aligned}
1-\frac{\partial \zeta_{m}}{\partial \kappa} & =1-\alpha>0 \\
1-\frac{\partial \zeta_{f}}{\partial(\psi-\kappa)}-w_{f} \frac{\partial \eta_{f}}{\partial(\psi-\kappa)} & =1-\alpha+\frac{1+w_{f}\left(\partial h_{f} / \partial x\right)}{\beta(\partial \alpha / \partial x)}>0 .
\end{aligned}
$$

if good $c$ is normal (for both spouses). Rearranging these expressions gives the second statement. 


\section{Appendix B : Alternative Estimations}

We carry out two alternative estimations of the model, with expenditures on food away from home and clothing as the conditioning good respectively. One problem, however, is that reported expenditures on clothing (resp. food away from home) are equal to zero for $7.5 \%$ (resp. 18\%) of the 1670 households of our selection. Be that as it may, these estimations are presented in Table 6. For the sake of comparability, the estimated parameters are obtained with the same set of instruments as those used for the regression in the main text. To complete these results, note that the parameters $B$ and $C$ of the Marshallian labor supply are significant at the $1 \%$ level when the conditioning good is food away from home; in that case, the parameters $K_{6}$ and $K_{9}$ are also significant (at the $5 \%$ and the $10 \%$ level). Furthermore, the Slutsky condition is satisfied for $92 \%$ of the sample, while conditions (a) and (b) of Proposition 4 are satisfied for $100 \%$ and $34 \%$ of the sample respectively. On the other hand, when the conditioning good is clothing, the results are less convincing. No parameters of the structural model are significant. The Slutsky condition is satisfied for $66 \%$ of the sample, and the conditions (a) and (b) are satisfied for $100 \%$ and $8 \%$ of the sample respectively. 
Table 6: Estimation with two alternative conditioning goods

\begin{tabular}{|c|c|c|c|c|c|}
\hline & & \multicolumn{2}{|c|}{ Unrestricted Model } & \multicolumn{2}{|c|}{ Restricted Model } \\
\hline & & $\begin{array}{l}\text { Food away } \\
\text { from home }\end{array}$ & Clothing & $\begin{array}{l}\text { Food away } \\
\text { from home }\end{array}$ & Clothing \\
\hline \multirow[t]{2}{*}{$a_{01}$} & $w_{f}$ & $5.406^{*}$ & $5.104^{* * *}$ & $4.169^{* *}$ & $4.018^{* * *}$ \\
\hline & & $(2.801)$ & $(1.881)$ & $(1.738)$ & $(1.021)$ \\
\hline \multirow[t]{2}{*}{$a_{02}$} & $\psi \times 10^{-2}$ & -0.059 & -0.054 & $-0.068^{*}$ & -0.043 \\
\hline & & $(0.050)$ & $(0.044)$ & $(0.041)$ & $(0.032)$ \\
\hline \multirow[t]{2}{*}{$a_{03}$} & $x$ & -0.001 & -0.003 & 0.002 & -0.000 \\
\hline & & $(0.007)$ & $(0.006)$ & $(0.004)$ & $(0.004)$ \\
\hline \multirow[t]{2}{*}{$a_{11}$} & $w_{f}^{2}$ & $-0.207^{*}$ & $-0.222^{* *}$ & $-0.142^{* * *}$ & $-0.139^{* * *}$ \\
\hline & & $(0.106)$ & $(0.092)$ & $(0.050)$ & $(0.040)$ \\
\hline \multirow[t]{2}{*}{$a_{22}$} & $\psi^{2} \times 10^{-9}$ & $5.879^{* *}$ & 2.504 & $6.010^{* *}$ & 2.394 \\
\hline & & $(2.969)$ & $(2.896)$ & $(2.751)$ & $(2.130)$ \\
\hline \multirow[t]{2}{*}{$a_{33}$} & $x^{2} \times 10^{-8}$ & 60.380 & 25.920 & 48.680 & 1.984 \\
\hline & & $(52.380)$ & $(50.360)$ & $(41.230)$ & $(9.804)$ \\
\hline \multirow[t]{2}{*}{$a_{12}$} & $w_{f} \psi \times 10^{-2}$ & 0.002 & 0.005 & 0.002 & 0.002 \\
\hline & & $(0.003)$ & $(0.004)$ & $(0.003)$ & $(0.003)$ \\
\hline \multirow[t]{2}{*}{$a_{13}$} & $w_{f} x / \times 10^{-2}$ & 0.017 & 0.031 & -0.017 & -0.006 \\
\hline & & $(0.050)$ & $(0.041)$ & $(0.022)$ & $(0.021)$ \\
\hline \multirow[t]{2}{*}{$a_{23}$} & $\psi x \times 10^{-9}$ & -193.000 & -134.000 & $-108.00^{*}$ & -13.800 \\
\hline & & $(132.400)$ & $(111.600)$ & $(59.570)$ & $(34.550)$ \\
\hline \multirow[t]{2}{*}{$\alpha_{0}$} & Intercept & 15.673 & $19.564^{*}$ & $22.412^{* *}$ & $23.100^{* * *}$ \\
\hline & & $(14.619)$ & $(10.231)$ & $(10.146)$ & $(6.109)$ \\
\hline \multirow[t]{2}{*}{$\alpha_{\mathrm{chi}}$} & Number of children & -0.244 & -1.019 & -0.162 & -1.169 \\
\hline & & $(0.868)$ & $(0.979)$ & $(0.766)$ & $(0.768)$ \\
\hline \multirow[t]{2}{*}{$\alpha_{\text {age }}$} & Wife's age & $-0.150^{* *}$ & $-0.144^{* *}$ & $-0.159^{* * *}$ & $-0.151^{* * *}$ \\
\hline & & $(0.062)$ & $(0.059)$ & $(0.051)$ & $(0.046)$ \\
\hline \multirow[t]{2}{*}{$b_{\lambda}$} & Inverse Mill's ratio & 3.355 & 1.599 & 1.924 & 0.974 \\
\hline & & $(3.624)$ & $(2.239)$ & $(2.815)$ & $(1.811)$ \\
\hline \multicolumn{2}{|c|}{ Objective function } & 6.391 & 7.4373 & 8.383 & 12.263 \\
\hline
\end{tabular}

Notes: Asymptotic standard errors in parentheses. Significance levels of

10,5 and $1 \%$ are noted $*$,** and $* * *$ respectively. 


\section{Appendix C : Auxiliary Regressions and Selection Equa- tion}

Table 7: Tests of the Validity of the Instruments

\begin{tabular}{lrrr}
\hline \hline & $F$-stat & $p$-Value & $\bar{R}^{2}$ \\
\hline The Fisher's test & & & \\
$1: w_{f}$ & 31.538 & 0.000 & 0.386 \\
$2: \psi$ & 8.644 & 0.000 & 0.157 \\
$3: x$ & 9.061 & 0.000 & 0.255 \\
$4: w_{f} \psi$ & 13.369 & 0.000 & 0.206 \\
$5: w_{f} x$ & 23.543 & 0.000 & 0.422 \\
$6: \psi x$ & 9.974 & 0.000 & 0.238 \\
$7: w_{f}^{2}$ & 16.494 & 0.000 & 0.277 \\
$8: \psi^{2}$ & 4.744 & 0.000 & 0.059 \\
$9: x^{2}$ & 7.386 & 0.000 & 0.209 \\
\hline The Robin-Smith's test & & & \\
$H_{0}: r k=i, H_{1}: r k>i$ & $i=1, \ldots, 7$ & 0.000 & \\
$H_{0}: r k=8, H_{1}: r k=9$ & & 0.000 & \\
\hline \hline
\end{tabular}

In Table 8, the wife's age is represented by dummies, Age ${ }_{i}$ with $i=1, \ldots, 6$. The age groups are $<30,31-34,35-39,40-44,45-49$ and $\geq 50$. The wife's education level is also represented by dummies, Educ E $_{i}$ with $i=1, \ldots, 7$, which represent the highest diploma attained by the wife. The unemployment rate is specific to gender and varies with age and education. It is denoted by $\operatorname{urate}_{i}$, with $i=m, f$. The statistics for the normality test is equal to 4.014 (with two degrees of freedom) which is acceptable at conventional levels. 
Table 8: Reduced Form Participation Probit

\begin{tabular}{|c|c|c|}
\hline & Parameters estimates & As. std. errors \\
\hline Intercept & $-17.413^{* * *}$ & 3.627 \\
\hline $\mathrm{Age}_{1}$ & $-0.892^{* * *}$ & 0.088 \\
\hline $\mathrm{Age}_{2}$ & $-0.495^{* * *}$ & 0.079 \\
\hline $\mathrm{Age}_{3}$ & reference & reference \\
\hline $\mathrm{Age}_{4}$ & $0.400^{* * *}$ & 0.086 \\
\hline $\mathrm{Age}_{5}$ & $0.335^{* * *}$ & 0.091 \\
\hline $\mathrm{Age}_{6}$ & $0.509^{* * *}$ & 0.110 \\
\hline Educ $_{1}$ & $-1.480^{* * *}$ & 0.194 \\
\hline $\mathrm{Educ}_{2}$ & $-0.865^{* * *}$ & 0.197 \\
\hline $\mathrm{Educ}_{3}$ & $-0.666^{* * *}$ & 0.126 \\
\hline $\mathrm{Educ}_{4}$ & $-0.699^{* * *}$ & 0.121 \\
\hline $\mathrm{Educ}_{5}$ & -0.188 & 0.133 \\
\hline Educ $_{6}$ & $-0.339^{* * *}$ & 0.109 \\
\hline $\mathrm{Educ}_{7}$ & reference & reference \\
\hline $\ln \left(w_{m} h^{m}\right)$ & $3.760^{* * *}$ & 0.745 \\
\hline $\ln ^{2}\left(w_{m} h^{m}\right)$ & $-0.202^{* * *}$ & 0.038 \\
\hline urate $_{m}$ & $0.055^{* * *}$ & 0.021 \\
\hline urate $_{f}$ & $0.067^{* * *}$ & 0.017 \\
\hline urate $_{m} \times$ urate $_{f}$ & $-0.003^{* *}$ & 0.001 \\
\hline Non-Normality (2) & 4.014 & $p$-Value $=0.134$ \\
\hline Skewness (1) & 3.129 & $p$-Value $=0.077$ \\
\hline Kurtosis (1) & 2.564 & $p$-Value $=0.109$ \\
\hline \multicolumn{3}{|c|}{ Non-Participants $=1096$, Participants $=1670$} \\
\hline
\end{tabular}

Note: Significance levels of 10,5 and $1 \%$ are noted ${ }^{*},{ }^{* *}$ and ${ }^{* * *}$ respectively. The statistics of tests have a $\chi^{2}$-distribution (degrees of freedom are in parentheses). The normality test statistics reported here follow the Generalised Residual methodology of Chesher and Irish (1987). 


\section{References}

Altonji J. G. (1986), "Intertemporal Substitution in Labor Supply: Evidence from Micro Data", Journal of Political Economy 94: S176-S215.

Altonji J. G. and A. Siow (1987), "Testing the Response of Consumption to Income Changes with (Noisy) Panel Data", The Quarterly Journal of Economics 102: 293-328. Apps P.F. and R. Rees (1997), "Collective Labour Supply and Household Production", Journal of Political Economy 105: 178-190.

Bloemen H.G. (2004), "An Empirical Model of Collective Household Labor Supply with Nonparticipation", Working Paper 010/3, Tinbergen Institute.

Blundell R. and F. Laisney (1988), "A Labour Supply Model for Married Women in France: Taxation, Hours Constraints and Job Seekers", Annales d'économie et de statistique 11: 41-71.

Blundell R. and I. Walker (1986), "A Life Cycle Consistent Empirical Model of Labour Supply Using Cross Section Data", Review of Economic Studies 53: 539-558.

Blundell R., A. Duncan and C. Meghir (1998), "Estimating Labor Supply Responses Using Tax Reforms", Econometrica 66: 827-861.

Blundell R., P.-A. Chiappori, T. Magnac and C. Meghir (2004), "Collective Labour Supply: Heterogeneity and Nonparticipation", Mimeo, University College of London.

Bound J., D. A Jaeger and R. M. Baker (1995), "Problems with Instrumental Variables Estimation When the Correlation Between the Instruments and the Endogenous Explanatory variable is Weak", Journal of the American Statistical Association 90: 443-450.

Bourguignon F. and T. Magnac (1990), "Labor Supply and Taxation in France", The Journal of Human Resources 25: 358-389.

Bourguignon F., M. Browning, P.A. Chiappori (1995), "The Collective Approach to Household Behaviour". Working Paper DELTA 95/04. 
Browning M. (1992), "Children and Household Economic Behavior", The Journal of Economic Literature 30: 1434-1475.

Browning M. (1998), "Modelling Commodity Demands and Labour Supply with mDemands". Working Paper University of Copenhagen.

Browning M. and C. Meghir (1991), "The Effects of Male and Female Labor Supply on Commodity Demand", Econometrica 59: 925-951.

Chavas J.P. (1984), "The Theory of Mixed Demand Functioms", European Economic Review 24: 321-344.

Chesher A.D. and M. Irish (1987), "Residuals and diagnostics for Probit, Tobit and related models", Journal of Econometrics 34: 33-61.

Chiappori P.A. (1988), "Rational Household Labor Supply", Econometrica 56 : 63-90.

Chiappori P.A. (1992), "Collective Labor Supply and Welfare", Journal of Political Economy 100: 437-467.

Chiappori P.A. (1997), "Introducing Household Production in Collective Models of Labor Supply", Journal of Political Economy 105: 191-209.

Chiappori P.A., R. Blundell and C. Meghir (2004), "Collective Labor Supply with Children", Working Paper, University of Chicago.

Chiappori P.-A., Fortin B. and G. Lacroix (2002), "Marriage Market, Divorce Legislation and Household Labour Supply", Journal of Political Economy 110: 37-72.

Clark A., Couprie H. and Sofer C. (2004), "La modélisation collective de l'offre de travail. Mise en perspective et application aux données britanniques", Revue Economique 55: $767-789$.

Davidson R. and J. G. MacKinnon (1993), Estimation and inference in econometrics, Oxford University Press.

Donni O. (2003), "Collective Household Labor Supply: Nonparticipation and Income Taxation", Journal of Public Economics 87: 1179-1198. 
Donni O. (2004), "A Simple Model of Collective Consumption", Working Paper, University of Cergy-Pontoise.

Donni O. (2005a), "Labor Supply, Home Production and Welfare Comparisons", Working Paper, IZA.

Donni O. (2005b), "Collective Models of the Household". Prepared for The New Palgrave Dictionnary of Economics, 2nd Edition.

Donni O. (2005c), "Collective Female Labor Supply: Theory and Application", Working Paper, IZA.

Fong Y. and Zhang J. (2001), "The Identification of Unobservable Independent and Spousal Leisure", Journal of Political Economy 109: 191-202.

Fortin B. and G. Lacroix (1997), "A Test of the Unitary and Collective Models of Household Labour Supply", Economic Journal 107: 933-955.

Graham J.W. and C.A. Green (1984), "Estimating the parameters of a household production function with joint production", Review of Economics and Statistics 66: 277-282.

Gronau R. (1977), "Leisure, home production and work — The theory of the allocation of time revisited", Journal of Political Economy 85: 1099-1123.

Manser M. and M. Brown (1980), "Marriage and Household Decision Making: A Bargaining Analysis", International Economic Review 21: 333-349.

McElroy M.B. and M.J. Horney (1981), "Nash-bargained Decisions : Toward a Generalization of the Theory of Demand", International Economic Review 22: 333-349.

Moreau N. and O. Donni (2002), "Estimation d'un modèle collectif d'offre de travail avec taxation", Annales d'économie et de statistique 65: 55-83.

Newey W. K. (1984), "A Method of Moments Interpretation of Sequential Estimators", Economics Letters 14: 201-206.

Newey W. K. and D. McFadden (1994), "Large Sample Estimation and Hypothesis Testing", Handbook of Econometrics 4: 2111-2245. 
Pollak R. (1969), "Conditional Demand Functions and Consumption Theory", Quarterly Journal of Economics 83: 60-78.

Robin J.M. and R.J. Smith (2000), "Tests of rank", Econometric Theory 16: 151-175. Ruud P.A. (2000), An Introduction to Classical Econometric Theory. Oxford University Press.

Staiger D. and J. H Stock (1997), "Instrumental Variables Regression with Weak Instruments", Econometrica 65:557-586.

Stern N. (1986), "On the specification of labour supply functions". In R. Blundell et I. Walker (eds). Unemployment, search and labour supply. Cambridge : Cambridge University Press.

Smith R.J. and R. Blundell (1986), "An Exogeneity Test fot the Simultaneous Equation Tobit Model",Econometrica 54: 679-685.

Vermeulen F. (2002), "Collective Household Models: Principles and Main Results", Journal of Economic Surveys 16: 533-564.

Vermeulen F. (2005), "And the Winner is... An Empirical Evaluation of Two Competing Approaches to Household Labour Supply", Empirical Economics (forthcoming). 